\title{
Legalismo moral y tolerancia. Crónica de una muerte anunciada
}

\author{
Moral Legalism and Tolerance \\ Chronicle of a Foretold Death
}

René González de la Vega*

Recepción y evaluación de propuesta: 20/2/2014

Aceptación: 20/03/2014

Recepción y aceptación final: 22/6/2015

Resumen: El presente trabajo versa sobre la pregunta en torno a la compatibilidad que puede haber entre el ideal moral de la tolerancia y la estructura de razonamiento práctico defendida por el liberalismo deontológico. En concreto, me refiero específicamente a la versión de esta clase de liberalismo que surgió a partir de la segunda mitad del siglo XX con la publicación de $A$ Theory of Justice de John Rawls; donde encontramos un desarrollo de la idea de tolerancia y el papel que desempeña en la resolución de conflictos prácticos.

Palabras clave: liberalismo, tolerancia, conflictos prácticos.

Abstract: This paper explores the question about the compatibility that may exist between the moral ideal of tolerance and the structure of practical reasoning defended by deontological liberalism. This is the kind of liberalism that arose in the second half of the twentieth century with the publication of John Rawls' A Theory of Justice; where we can find a development of the idea of tolerance and the role it plays solving practical conflicts.

Key words: liberalism, tolerance, practical conflicts.

* Universidad Nacional Autónoma de México.

E-mail: gonzalezdelavega@yahoo.com. 


\section{I.}

Uno de los presupuestos centrales del moderno liberalismo deontológico es el de estar construido sobre la base de una filosofía de la tolerancia. La tolerancia es la promesa normativa que el liberalismo ofrece para dirimir los conflictos de valores que se pueden dar entre personas razonables. Por eso, Rawls aplica la tolerancia a la filosofía misma. La ve como una virtud central que ayuda a solucionar el problema básico de las sociedades democráticas modernas: ¿cómo es posible que pueda existir una sociedad justa y estable de individuos libres e iguales que se encuentran profundamente divididos por distintas concepciones razonables del bien? ${ }^{1}$ De la misma manera en que Rawls piensa que la tolerancia es la promesa normativa que le permite al liberalismo resolver esta clase de conflictos que se dan entre personas razonables, así también lo piensan filósofos como Ernesto Garzón, Rainer Forst, Charles Larmore, Tim Heysse, Thomas Nagel o Rodolfo Vázquez.

Este sentir es el de muchos liberales contemporáneos que sostienen que la tolerancia se encuentra en el "corazón" del liberalismo². Por eso, para ellos, hablar de un "liberalismo tolerante" se torna en un pleonasmo pues el uno incluye al otro como el reverso y el anverso de una misma moneda.

Esta clase de afirmaciones no pueden pasar desapercibidas al ojo crítico de un lector atento. Ambos conceptos son sumamente complejos como para determinar sin más una armonía pacífica entre ellos. El punto central que defiendo en este trabajo es precisamente el contrario al que defienden los liberales deontológicos, este es: esta clase de liberalis-

1 Rawls, J., Political Liberalism, Political Liberalism, Nueva York, Columbia University Press, 1996, pág. 49.

2 Heyd, D., "Introduction", Toleration. An Elusive Virtue, Elusive Virtue, Princeton, Princeton University Press, 1998, pág. 3; Camps, V., "Pluralismo y tolerancia”, en Bermudo Ávila, J. (ed.) Retos de la Razón Práctica, Barcelona, España, Universidad de Barcelona, 2002, pág. 59; Cohen, A.J., "What Toleration Is?" Ethics, 115, 2004, pág. 68; Gray, J., Two Faces of Liberalism, Nueva York, The New Press, 2000, pág. 2; Silva-Herzog Márquez, J., "Razones para la tolerancia", en Vázquez, R. (comp.), Tolerancia y pluralismo, Ciudad de México, México, Ediciones Coyoacán, 2005, pág. 85. 
mo es incompatible con la clase de tolerancia que ellos dicen defender.

Antes de esto, es importante notar que en este trabajo no abordaré cuestiones relacionadas con la historia de la tolerancia, ni tampoco me ocuparé de lo que, en otros momentos y en otros lugares, filósofos de la moral o de la política han dicho sobre este concepto. La pregunta que trataré de contestar no tiene que ver con cuestiones prácticas que rodean el tema de la tolerancia en general como: ¿qué es tolerable?, ¿qué es intolerable? o, ¿cuáles son los límites de la tolerancia? Tampoco propondré una forma distinta de comprender la tolerancia que resulte atractiva frente a determinados problemas prácticos que enfrenta el liberalismo. Indudablemente, todos estos temas y problemas son interesantes en sí mismos, sin embargo, el problema que tengo en mente es de distinto calado. Es un problema que podríamos calificar como un problema de coherencia filosófica, el cual consiste en la compatibilidad que puede haber entre el ideal moral de la tolerancia y la estructura de razonamiento práctico defendida por el liberalismo deontológico. Para evitar problemas de muchos tipos me referiré específicamente a la versión de esta clase de liberalismo que surgió a partir de la segunda mitad del siglo XX con la publicación de $A$ Theory of Justice de John Rawls.

Al decir esto no quiero implicar que la teoría de Rawls vaya a ser la única diana de mis críticas. Por el contrario, pretendo que las conclusiones defendidas en las páginas que siguen sean aplicables a todo tipo de liberalismo deontológico y no únicamente al liberalismo político defendido por Rawls. Si hago mención de su teoría es solo para delinear una frontera que marca un antes y un después dentro de la historia de la filosofía política y moral contemporánea.

Como se sabe, antes de la teoría de la justicia de Rawls el panorama discursivo en temas de filosofía moral y política estaba de alguna forma empantanado. Las discusiones en filosofía moral se encontraban encapsuladas por dos corrientes distintas que pretendían dar respuestas definitivas a todos los problemas prácticos: el utilitarismo y el intuicionismo. Lo mismo sucedía en el ámbito de la filosofía política, la cual se había visto sumergida en un debate estéril entre visiones dogmáticas que defendían alguna versión del marxismo o del capitalismo como los 
únicos parámetros para resolver problemas de justicia social. Bajo ese panorama, la teoría de la justicia de Rawls surgió como brisa de verano reviviendo muchos temas y problemas de la filosofía práctica que, en general, se habían visto abandonados por aquellas corrientes que dominaban el escaparate filosófico. Fundamentalmente, Rawls revivió la filosofía kantiana como una perspectiva competitiva que volvía a poner en el centro del debate moral la autonomía de las personas y una perspectiva contractualista que servía como método racional para la fundamentación de los principios de justicia. Sus ventajas eran claras: la teoría proponía una estructura política que estaba igualmente preocupada por defender la libertad individual como por abatir las desigualdades existentes dentro de las sociedades democráticas modernas.

En Facing Diverstiy: The Case of Epistemic Abstinence, Joseph Raz comentó que la teoría de la justicia de Rawls era distintiva al resto de teorías porque enfrentaba los aspectos centrales de nuestras sociedades, los problemas más fundamentales sobre la distribución del poder, de los recursos y de la jerarquía social de los individuos [...] su teoría, a través de la defensa y del uso del equilibrio reflexivo como método y de argumentos contractualistas revivió temas aristotélicos y kantianos, y prometía un método para resolver mediante argumentos racionales las viejas disputas sobre moralidad política ${ }^{3}$.

Ciertamente, el éxito que esta clase de liberalismo ha tenido en la actualidad se debe a las muchas ventajas prácticas y filosóficas que el deontologismo ha presentado: este representa una perspectiva robusta de la justicia social, ha propuesto la teoría dominante sobre los derechos individuales, ha aportado mecanismos para la evaluación de las instituciones públicas, pero, sobre todo, ha representado el mecanismo más aplaudido hasta el momento para la justificación moral de los principios básicos de justicia.

Señalar la incompatibilidad que hay entre el liberalismo deontológico y el ideal moral de la tolerancia no pretende restar importancia a

3 Raz, J., "Facing Diversity: The Case of Epistemic Abstinence", en Raz, J., Ethics in the Public Domain. Essays in the Morality of Law and Politics, Oxford, Clarendon Press, 1995, págs. 61-62. 
ninguno de esos factores del liberalismo deontológico. Mi argumento no pretende "avergonzar", como alguna vez comentaron Tim Heysse y Raf Geenens sobre mi trabajo, a los liberales contemporáneos haciéndoles ver que construyeron sus teorías con piezas que, en realidad, pertenecían a distintos rompecabezas. Por el contrario, el ánimo de mi crítica está dirigido a denunciar una inconsistencia que encuentro dentro de su estructura y que puede ser fácilmente salvada por sus defensores. En realidad, dada la concepción del razonamiento moral que esta clase de liberalismo defiende, debe prescindir de la tolerancia como mecanismo para la resolución de cierta clase de conflictos prácticos - a diferencia de otras versiones del liberalismo, como, por ejemplo, el perfeccionismo liberal en sus distintas versiones o alguna clase de republicanismo, que sí la necesitan-.

Al contrario de lo que podría suponerse con mi crítica, me parece que el liberalismo deontológico cuenta con recursos de razonamiento práctico lo suficientemente efectivos como para cumplir con esos propósitos. El juicio acerca de qué clase de liberalismo es mejor: si un liberalismo coherente con los requerimientos de la tolerancia o un liberalismo que no requiera de dicho concepto, es una pregunta que no trataré de responder en estas páginas. No obstante, estoy convencido de que el liberalismo deontológico, por esta clase de problemas y dada la concepción legalista de la moral que sostiene, tiene una capacidad práctica mucho más reducida y es mucho más propensa a convalidar la indiferencia ética y a fomentar la imposición de la moral.

En los primeros dos puntos limpiaré un poco el ámbito de penumbra conceptual y teórica en la que podría sumergirse mi crítica. Primero, presentaré una definición breve de lo que entiendo por "liberalismo deontológico" (punto II.), dando una explicación sobre las características conceptuales que, según sostengo, definen esta clase de teoría. A continuación, en el punto III., discutiré la forma en que ciertos liberales deontológicos han discutido la justificación y la conceptualización de la tolerancia. Por razones de espacio en este punto haré mayor énfasis en los modelos de Ernesto Garzón Valdés y Rainer Forst, con algunas anotaciones relativas a la concepción del razonamiento práctico de Rawls. Estos dos primeros puntos serán sumamen- 
te descriptivos. Sugiero que aquellos lectores que conocen estos temas o están familiarizados con estos autores pasen directamente a las secciones posteriores donde se encuentran los argumentos que ofrezco para defender la incompatibilidad entre el liberalismo deontologista y la tolerancia como ideal moral.

En esos puntos (IV., V. y VI.), discutiré tres distintas clases de problemas: (i) que la tolerancia es impracticable cuando se trata de conflictos morales profundos (punto V.), (ii) que la tolerancia se convierte en un mecanismo tiránico de la moral liberal (punto IV.), y (iii) que la tolerancia se torna suicida ${ }^{4}$ estando en las manos del liberalismo deontológico (punto VI.). En el punto VII., presentaré alguna nota a manera de conclusión para cerrar este trabajo, donde abundaré en la idea del legalismo moral.

\section{II.}

Para ir preparando el terreno de discusión en lo que sigue diré qué entiendo por "liberalismo deontológico". Lo entiendo como una teoría de la justicia que está estructurada bajo una concepción específica del razonamiento práctico que tiene tres características básicas o centrales:

Define lo "correcto" independientemente de lo "bueno".

Lo "correcto" tiene prioridad sobre lo "bueno".

Lo "correcto" no está dirigido a maximizar lo "bueno".

Estas características derivan de algunos presupuestos filosóficos propios del deontologismo. No me ocuparé de todos aquí, pero hay uno de ellos que debemos mencionar pues resulta central para comprender su estructura del razonamiento práctico. Me refiero a la distinción entre "moral" y "ética" o entre lo "correcto" y lo "bueno" o entre "justicia" y las "concepciones del bien" 5 . Como sabemos, en la teoría de Rawls esta

4 En ese punto explico qué entiendo por el término "suicida" y de qué forma lo utilizo para referirme a un concepto normativo como el de la "tolerancia".

5 Es importante no perder de vista que hago uso de estos términos de manera intercambiable. Esto se debe a que cuando los liberales deontológicos ha- 
diferencia es el producto del binomio "racional-razonable" que hace referencia a los dos poderes morales de los individuos: crear y promover una concepción del bien y tener un sentido de justicia ${ }^{6}$.

Si rastreáramos genealógicamente los orígenes de esta distinción, veríamos que esta se refiere a la vieja disputa entre la "Moralität" kantiana y el "Sittlichkeit" hegeliano7. Mientras que la "justicia" o lo "correcto" están alineados con la idea kantiana de la Moralität, la "ética" o las "concepciones del bien" lo están con el Sittlichkeit hegeliano.

Para los filósofos morales afiliados al deontologismo, la ética o concepciones del bien responden a cuestiones relacionadas con la forma en que debemos vivir nuestras vidas. Responden a preguntas del tipo: ¿qué vida debo vivir?, ¿cuál es la vida que merece la pena ser vivida?, ¿cuál es mi lugar en el mundo?, ¿qué clase de persona quiero ser?, etc. En cambio, la moral, la justicia, responde a preguntas relacionadas a: ¿Cómo debemos tratar a otras personas? ¿Cómo debemos comportarnos con nuestros congéneres, con nuestros conciudadanos, con nuestros colegas? Responde a preguntas como: ¿qué clase de conductas están permitidas?, ¿cuáles prohibidas? ${ }^{8}$ Siendo así, para esta clase de filósofos las cuestiones éticas son personales y particulares, mientras que las cuestiones morales reclaman validez y aceptación universal ${ }^{9}$.

1) Regresemos a las tres características centrales que definen esta clase de liberalismo. La independencia de la "moral" frente a la "ética"

blan de "justicia" es porque se refieren al ámbito de la "moral", que es el ámbito de lo "correcto", y cuando hablan de lo "bueno" hacen referencia a las distintas "concepciones del bien" que pertenecen al mundo de la "ética" y no de la "moral".

6 Rawls J., Political Liberalism, op. cit., pág. 37.

7 Fraser N., "Recognition without ethics?", en McKinnon C. y Castiglione D., The Culture of Toleration in Diverse Societies. Reasonable Tolerance, Manchester, Manchester University Press, 2003, págs. 86-108; Charles Taylor, Hegel and Modern Society, Cambridge, Cambridge University Press, 1979, págs. 83-84.

8 Dworkin, R., Justice for Hedgehogs, The Belknap Press of Harvard University Press, 2011, págs. 25.

9 Heysse T. y Segaert, B., "Perplexities of Tolerance", Bijdragen. International Journal in Philosophy and Theology, 71(4), 2010, págs. 355. 
se refiere a que los principios de justicia no deben estar fundamentados a partir de concepciones particulares del bien ni que deben aportar razones que nos digan porqué todos debemos aceptarlos como válidos; razones que deben ser independientes o autónomas respecto de las concepciones del bien. Esto se debe, fundamentalmente, a que si la moral reclama validez universal, la ética no puede ser parangón de la justicia por ser particular y personal.

Repárese en que no todas las teorías deontológicas entienden el criterio de independencia de la misma manera. Sin duda alguna, entender la independencia como autonomía de la moral frente a la ética es la marca distintiva de una corriente del deontologismo liberal que fue denominado por J. Rawls como "liberalismo político"10. Esto es aquella clase de liberalismo que pretende buscar los fundamentos de la justicia en la imparcialidad para no recurrir a ninguna concepción del bien. La imparcialidad juega aquí el papel de un punto arquimedeano mediante el cual se pretende llegar a un acuerdo sobre la moral sin recurrir a nuestras creencias personales. Sin embargo, hay liberalismos deontológicos, como el del último Dworkin, que distinguen entre la "moral" y la "ética", empero, que no consideran que la moral pueda sostenerse en completa independencia epistémica frente a la ética. Para autores como Dworkin, la moral se alimenta de la ética, aunque también considera que este paso requiere de razones distintivas que soporten las razones éticas en un ámbito de universalidad ${ }^{11}$.

A pesar de que esta postura defiende la idea de que la moral se alimenta normativamente de la ética, también reconoce la distinción entre "moral" y "ética" como distintas esferas del mundo normativo.

${ }^{10}$ Rawls, J., "Justice as Fairness: Political not Metaphysical", en Freeman, S., (ed.), John Rawls. Collected Papers, Cambridge, Harvard University Press, 2001.

${ }^{11}$ Este punto fue defendido y desarrollado por Dworkin de manera explícita y clara en su libro Justice for Hedgehogs. En este Dworkin dice: "[..] to integrate ethics with morality, not simply by incorporating morality into ethics but by achieving a mutually supportive integration of the two in which our thoughts about living well help us to see what our moral responsibilities are: an integration that responds to the traditional philosopher's challenge about what reason we have to be good". Dworkin, R., op. cit., pág. 255. 
Esto implica que bajo esta concepción también se sostiene la independencia conceptual de una esfera frente a la otra. Es por esto que sostengo que esta característica es un elemento conceptual del liberalismo deontológico y no únicamente del "liberalismo político" defendido por autores como Rawls o Larmore, entre otros.

2) Ahora bien, la independencia de la moral frente a la ética no termina de explicar la prioridad que se argumenta tiene la "moral" sobre la "ética". Según Michael Sandel, la prioridad de la moral sobre la ética deriva de dos reclamos distintos que encontramos en el seno de las teorías deontológicas:

el primero es el reclamo según el cual ciertos derechos individuales son tan importantes que ni siquiera el bienestar general puede derrotar. El segundo es el reclamo según el cual los principios de justicia que especifican nuestros derechos no dependen para su justificación de ninguna concepción del bien o, como Rawls lo ha puesto, no deben derivar de ninguna concepción comprehensiva religiosa o moral ${ }^{12}$.

Por tanto, la prioridad de la moral sobre la ética se sostiene sobre la base de dos distintas clases de argumentos que aunque distinguibles se entrelazan. El primero de ellos es un argumento moral y el otro un argumento epistemológico. Según el argumento epistémico, la justicia es prioritaria sobre el bien porque a los principios de justicia los respalda una justificación independiente o autónoma de la cual no gozan las distintas concepciones del bien, por ser subjetivas y parciales. En términos rawlsianos, esta justificación de la que hacen alarde los deontologistas sobre los principios de justicia es el producto o de una decisión colectiva generada a través de un "consenso traslapado" (Rawls ${ }^{13}$ y Larmore ${ }^{14}$ )

${ }^{12}$ Sandel, M.J., Public Philosophy. Essays on Morality in Politics, Cambridge, Harvard University Press, 2005, pág. 217.

13 Rawls, J., "The idea of an Overlapping Consensus" (1987), Freeman, S. (ed.), op. cit., págs. 421-448.

${ }^{14}$ Larmore, C., Patterns of Moral Complexity, Cambridge, Cambridge University Press, 1987. 
o es el resultado de una clase de argumento ético que añade razones objetivas que todos, en tanto agentes racionales, logran aceptar (Dworkin $^{15}$, Scanlon ${ }^{16}$ o Garzón ${ }^{17}$ ). De tal suerte que los principios de justicia cuentan con una justificación que parte de una posición imparcial $u$ objetiva no sesgada o "arraigada" a factores contingentes de la sociedad en que vivimos, como las tradiciones, las costumbres, los perjuicios o las diversas doctrinas particulares que dominan el pensamiento de una comunidad. Esta clase de justificación hace que los derechos individuales que derivan de los principios de justicia protejan la individualidad y la integridad de todas las personas. De ahí que los derechos individuales se consideren tan importantes que no puedan ser derrotados por ninguna otra consideración normativa.

3) La última característica central de las teorías deontológicas y que las distingue de las teorías consecuencialistas, en general, es la de no contemplar como criterio de corrección moral la maximización del bien. Todos aquellos lectores familiarizados con los debates en filosofía moral saben bien que la diferencia es crucial para comprender las implicaciones prácticas que acarrean ambas teorías morales. Mientras que las utilitaristas, en particular, y las consecuencialistas, en general, consideran que las acciones moralmente correctas son aquellas que maximizan el bien, las teorías deontológicas consideran que las acciones son correctas en tanto en cuanto estas respeten el deber moral independientemente de las consecuencias (benéficas o perjudiciales) que esto contraiga. El deber moral es impuesto por un sistema de reglas o de principios preestablecidos y autónomamente aceptados ${ }^{18}$.

${ }^{15}$ Dworkin, R., Justice for..., op. cit.

${ }^{16}$ Scanlon, T.M., What we owe to each other, Cambridge, The Belknap Press of Harvard University Press, 1998.

${ }^{17}$ Garzón Valdés, E., "¿Puede la razonabilidad ser un criterio de corrección moral?", en Garzón Valdés, E., Instituciones Suicidas. Ensayos de Ética y Politica, México, Paidós-UNAM, 2000.

${ }^{18}$ Pettit, P., "Consequentialism and Respect for Persons", Ethics, 100, 1, 1989, págs. 116-126. 


\section{III.}

Ya enumeradas estas tres características del liberalismo deontológico, ahora veremos qué entienden los filósofos de esta corriente por "el ideal moral de la tolerancia". En la literatura especializada se ha aceptado de manera más o menos pacífica que el concepto de tolerancia está compuesto por tres elementos (algunos autores los llaman "circunstancias"19, otros los denominan "condiciones"20, sin embargo, todos se refieren en términos generales a lo mismo) que son necesarios y suficientes: 1) la existencia de un acto que lesione una convicción relevante, 2) tener el 'poder' o la 'competencia adecuada' para detener, frenar u obstaculizar el acto que lesionó nuestra convicción y, 3) ponderar el valor de la convicción lesionada con razones que nos invitan a no intervenir en contra del acto en cuestión.

A pesar de la aceptación de esta estructura conceptual, en la actualidad sigue existiendo un amplio desacuerdo sobre la evaluación de los elementos que estructuran dicho concepto: qué se entiende por "convicción relevante", por "poder", por "competencia adecuada", qué razones pueden justificar un acto de tolerancia, entre muchos otros. Estos desacuerdos han logrado dividir el debate sobre la tolerancia en una serie de posturas irreconciliables que van desde aquellas que no le atribuyen ningún valor moral hasta las que defienden que la tolerancia es un valor en sí mismo. Asimismo, se encuentran aquellas que consideran que la tolerancia se justifica con cualquier clase de razones frente a quienes dicen que la tolerancia solo se puede justificar

${ }^{19}$ Véase, Garzón Valdés, E., "'No pongas tus sucias manos sobre Mozart"”. Algunas consideraciones sobre el concepto de tolerancia", en Garzón Valdés, E., Instituciones Suicidas. Estudios de ética y polítca, op. cit., pág. 182; Schmitt, A., "Las circunstancias de la tolerancia", Doxa. Cuadernos de Filosofia del derecho, 1, 1992.

${ }^{20}$ Véase, Newey, G., Virtue, Reason and Toleration. The Place of Toleration in Ethical and Political Philosophy, Edinburgh, Edinburgh University Press, 1999, pág. 21.

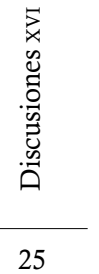


a través de razones morales. También están aquellos que consideran que la tolerancia es el sustento teórico del escepticismo o del relativismo moral, hasta aquellas que consideran que la tolerancia solo forma parte de una postura objetivista ${ }^{21}$.

De cierto modo, esto es como lo ha señalado Rainer Forst en su Toleration in Conflict: "solo hay un concepto de tolerancia, sin embargo, a lo largo de la historia se han desarrollado distintas concepciones las cuales han entrado en conflicto"22.

A pesar de esta diversificación de significados, concepciones y criterios de justificación, los filósofos afiliados al liberalismo deontológico sostienen que la tolerancia es un ideal moral (o una propiedad disposicional o una virtud de la justicia) que solo puede justificarse a través de razones morales. Entiéndase que para esta clase de filósofos la tolerancia es una virtud de la justicia a la que solo tienen acceso aquellas personas razonables que han desarrollado un sentido de justicia (en el sentido que Rawls le da a los términos de "razonable" y "sentido de la justicia") ${ }^{23}$.

Sin embargo, una forma de explicar las diferencias entre la concepción adoptada por el liberalismo deontológico y el resto de las concepciones sobre la tolerancia es a través de la contraposición que hay entre una visión instrumental de la tolerancia basada en la idea del "poder" y otra valorativa basada en una "noción moral". Pero esto, sin duda, son términos muy generales. Hay por lo menos dos diferencias que me gustaría exponer de manera más detallada pues, además, nos permitirán acceder a los argumentos que tengo pensado presentar.

La primera de ellas se refiere a la forma en que los liberales deontológicos han entendido el primer "elemento" o "circunstancia" de la

${ }^{21}$ Para un análisis sobre estos desacuerdos véase, González de la Vega, R., "Desacuerdos en el concepto de tolerancia", Jurídica. Anuario del Departamento de derecho de la Universidad Iberoamericana, No. 37, 2007, México, págs. 373-394.

${ }^{22}$ Forst, R., Toleration in Conflict. Past and Present, Cambridge, Cambridge University Press, 2013, págs. 3.

${ }^{23}$ Rawls, J., Political Liberalism, op. cit., pág. 48 y ss; Forst, R., "Toleration, Justice and Reason”, McKinnon, C. y Castiglione, D. (ed.), op. cit., pág. 78. 
tolerancia. Específicamente, esta se refiere a la lesión de una convicción relevante. Filósofos como Peter Nicholson ${ }^{24}$, por ejemplo, piensan que las únicas convicciones que pueden ser candidatas para la tolerancia son las convicciones morales. Nicholson argumenta esto a partir de la distinción entre dos tipos de rechazo: Dislike y Disapproval. Nicholson define el primero como un rechazo basado en nuestras emociones y pasiones y que, por lo tanto, no puede ser objeto de deliberación racional. Al segundo, en cambio, lo define como un rechazo racional que puede ser objeto de argumento ${ }^{25}$.

Ernesto Garzón Valdés, Rainer Forst, y John Rawls, en cambio, consideran que restringir el tipo de rechazos que pueden dar pie a un acto de tolerancia únicamente a rechazos morales, como diría Nicholson, sería una forma de reducir el ámbito de la tolerancia de manera innecesaria. En el caso de Garzón y Forst específicamente, ambos contemplan la posibilidad de que la clase de rechazos que pueden originar actos de tolerancia provengan de convicciones morales, éticas, estéticas, de gustos o preferencias ideológicas o religiosas. En el caso de Rawls, cuando él se refiere a las clases de convicciones que pueden entrar en el ámbito de la tolerancia lo hace con referencia al ámbito de lo "racional". Como ya lo mencioné antes, para Rawls este ámbito se distingue del ámbito de lo "razonable". El primero incluye lo que Rawls llama "concepciones comprehensivas del bien", el otro contempla lo que él denomina "sentido de justicia" (reconocimiento y aceptación de los principios de justicia). Dentro de la misma teoría de Rawls, las concepciones del bien pueden contemplar creencias, intereses y deseos de muy diversos tipos y con fuentes de justificación diversas: filosóficas, ideológicas, religiosas, etc. Esto nos invita a pensar que Rawls, en principio, también estaría en desacuerdo con Nicholson.

Sin embargo, es cuestión de analizar las cosas más de cerca y ser caritativos en nuestra interpretación. Es posible que Nicholson esté usando el término "moral" de una manera sumamente amplia y flexi-

${ }^{24}$ Nicholson, P., "Toleration as a Moral Ideal", London: New York, Methuen (ed.), Aspects of Toleration. Philosophical Studies, London: New York, Methuen, 1985, págs. 158-173.

${ }^{25}$ Nicholson, P., op. cit., pág. 160. 
ble, puesto que la verdadera distinción que hace es cuando habla sobre convicciones racionales y convicciones no racionales - es decir, convicciones que pueden ser objeto de argumento y que no pueden ser objeto de argumento- - Si este es el caso, entonces, los tres autores antes mencionados estarían de acuerdo con la distinción que hace Nicholson. Por ejemplo, incluir en el ámbito de lo tolerable cuestiones que se refieren a gustos y preferencias personales, siempre y cuando puedan ser expresados a través de razones. Cuestiones que se refieran a gustos, pero que no estén basadas en razones y que por ello no puedan ser objeto de argumento, no entrarían en el ámbito de lo (in)tolerable.

Independientemente del debate sobre si las emociones, los gustos o las preferencias personales pueden ser racionales o no (sustentadas en razones) y, por tanto, objeto de argumento, lo interesante de este punto es que todos estos autores consideran que la tolerancia no solo se aplica a cuestiones morales, sino a cuestiones que pertenecen a diversos ámbitos normativos. Lo que esto quiere decir es que los desacuerdos que involucran actos de tolerancia pueden derivar de cuestiones relativas a la moral, a concepciones éticas, religiosas, ideológicas, estéticas, entre muchas otras posibilidades.

Este punto es sumamente interesante tomando en cuenta la segunda característica adoptada por los filósofos del deontologismo. Me refiero al mecanismo para la justificación de la tolerancia. Así llegamos al segundo punto que quería abordar antes de entrar en la discusión central de este trabajo.

La separación entre moral y ética asumida por el deontologismo moral les ha servido a esta clase de filósofos como la estructura central para la justificación de la tolerancia. Por ejemplo, en el caso de Ernesto Garzón Valdés, él afirma que la tolerancia está doblemente referida a sistemas normativos. Por un lado, indica que la tendencia a no permitir el acto finalmente tolerado proviene del sistema a cuya regulación está sujeto. A este sistema lo bautiza con el nombre de "sistema normativo básico"26. Este sistema normativo básico es el que 
define el tipo de tolerancia del que se trata: moral, religiosa, científica, estética, política, y hasta de convenciones y de moda.

Por otro lado, la superación de esa tendencia a prohibir un acto "es el resultado de la consideración de principios y reglas de un sistema normativo superior" 27 . A este otro sistema lo bautiza con el nombre de "sistema normativo justificante". A él pertenecen las razones justificantes últimas, es decir, las razones morales.

Esto es, de los distintos "sistemas normativos básicos" se desprenden las distintas clases de convicciones que un individuo puede llegar a defender, que, a su vez, son las que definen el tipo de tolerancia del que se trata. Del "sistema normativo justificante" se desprenden las razones últimas que nos invitan a no intervenir cuando un acto lesiona alguna de aquellas convicciones derivadas del sistema básico en cuestión.

La decisión de tolerar algo, según Garzón, se resuelve gracias a la interacción que se produce entre ambos sistemas normativos. Esto es, si un acto $X$ está prohibido dentro del sistema normativo básico, lo que la tolerancia requiere en este caso es que dicha prohibición sea evaluada por el sistema normativo justificante.

Repárese en el hecho de que no es necesario que de esta evaluación surja un acto de tolerancia frente a $X$. Aunque puede darse el caso de que el sistema justificante reafirme la prohibición contenida en el sistema básico y, en consecuencia, esta no sea derogada ${ }^{28}$. Cuando sucede esto, el sistema básico se moraliza cerrando las puertas a la tolerancia, o por decirlo de algún modo, fortaleciendo el cerco de lo no tolerable ${ }^{29}$.

En suma, el acto objeto de tolerancia, por definición, debe estar prohibido en un sistema normativo básico. La prohibición solo puede ser levantada por las razones que provienen de un sistema justificante. Se resuelve tolerar el acto $X$ mediante un delicado equilibrio entre el

\section{Idem.}

28 Utilizo el mismo término que Garzón usa en el texto que vengo citando.

${ }^{29}$ Garzón Valdés, E., "El sentido actual de la tolerancia", en Alexy, R., Teoría del discurso y derechos constitucionales, Ciudad de México, Fontamara, 2004, pág. 14. 
sistema básico y el justificante. Si el conflicto que causa $X$ entre el sistema básico y el justificante es superado, ya no puede hablarse de tolerancia. La tolerancia basada en un sistema justificante moral conlleva a una moralización del sistema básico ${ }^{30}$.

La concepción de Forst no dista mucho de la defendida por Garzón. Para Forst, las normas morales no se pueden justificar sobre la base de consideraciones éticas sino a través de un proceso intersubjetivo. Dado que no existen verdades morales trascendentales, de acuerdo con Forst, la única forma de lograr una validez moral es sometiendo las consideraciones prácticas a un procedimiento discursivo que les permita ser parte de un acuerdo razonable, el cual no pueda ser rechazado por razones generales y recíprocas.

Los criterios de generalidad y reciprocidad responden a los criterios arquetípicamente kantianos de universalidad e imparcialidad. Cuando Forst habla de "generalidad", se refiere a que las razones que justifican la validez de una norma moral deben ser aceptadas por todas las partes involucradas y no, únicamente, por algunas de las partes. Tim Heysse sostiene que la idea de 'reciprocidad' en Forst puede entenderse de dos distintas maneras: una, como "reciprocidad de contenido" y, otra, como "reciprocidad de razones". La primera implica que " $A$ ' no puede reclamar un derecho o un atributo que le niega a ' $\mathrm{B}$ "' ${ }^{1}$. La segunda se refiera a las razones que damos a favor de un reclamo normativo, que deben estar abiertas a que sean cuestionadas por cualquiera y no por un grupo de personas determinado ${ }^{32}$.

Estos dos criterios de justificación moral constituyen lo que Forst ha denominado el principio de justificación. Las normas que estén fundamentadas a partir de este principio de justificación se deben considerar como categóricas y con una incondicional fuerza vinculante. En palabras de Forst:

${ }^{30}$ En el mismo sentido véase, Navarro, P., "Reflexiones acerca del concepto de tolerancia", Doxa, 13, 1993, pág. 279.

${ }^{31}$ Heysse, T., "Toleration and Political Conflict. A comment on Rainer Forst's Analysis of Toleration", Bijdragen. International Journal in Philosophy and Theology, 7, 4, 2010, pág. 398. 
La fuerza de un reclamo moral válido consiste en que nadie tiene buenas razones para cuestionar su validez y en que nadie puede, en principio, demandar a alguien más que no cumpla con sus mandatos ${ }^{33}$.

Esta fuerza "categórica" e "incondicional" que las normas morales obtienen por vía del principio de justificación (reciprocidad y generalidad) no es compartida por ninguna otra clase de normas (éticas, religiosas, prudenciales, instrumentales, estéticas, etc.). Esto implica que no puede haber criterios normativos racionales que estén por encima de los morales. Esta perspectiva lo lleva a decir que si la tolerancia es entendida como una virtud de la justicia, debe entonces estar guiada por el principio de justificación. Si la objeción inicial está basada en nuestras concepciones éticas (o religiosas) personales, la aceptación o el rechazo deben estar basados en una consideración moral que pueda ser universalmente aceptada. Cuando las consideraciones contenidas en la objeción resultan ser suficientes para emitir un juicio ético negativo, pero no suficientes para emitir un juicio moral negativo, es cuando debe ejercitarse la tolerancia; es decir, no intervenir en contra del acto que generó dicha objeción. Es en estos casos cuando uno debe darse cuenta de que nuestras consideraciones éticas no son suficientes para justificar un reclamo generalizado sobre ciertas prácticas individuales $^{34}$. Ahora bien, si las razones éticas son suficientes para emitir un juicio moral negativo, luego entonces, no hay acto que se deba tolerar y nuestra obligación es actuar conforme a la valoración moral.

El esquema propuesto por estos dos autores refleja de manera más o menos fiel la idea central defendida por Rawls cuando explica la interacción entre lo racional y la razonabilidad. Ambas constituyen lo que Rawls denomina "los dos poderes morales" de los individuos:

la capacidad de un sentido de justicia y la capacidad de generar una concepción del bien. El sentido de justicia es la capacidad de entender, aplicar y actuar según la concepción de la justicia

${ }^{33}$ Forst, R., The Right to Justification. Elements of a Constructivist Theory of Justice, Nueva York, Columbia University Press, 2007, pág. 49.

${ }^{34}$ Ibid., pág. 148. 
que caracteriza a los términos justos de la cooperación social. Dada la naturaleza de la concepción política, en tanto que especifica una base pública de justificación, el sentido de la justicia también expresa la disposición, la voluntad, si no es que el deseo, de actuar en relación con los demás ciudadanos en términos que ellos también puedan suscribir públicamente. La capacidad de adoptar una concepción del bien es la de conformar, examinar y buscar, racionalmente una concepción de una ventaja o bien racional propio ${ }^{35}$.

La distinción rawlsiana entre lo razonable y lo racional responde a la tradicional distinción kantiana entre el imperativo categórico y el imperativo hipotético, respectivamente ${ }^{36}$. En este sentido, para Rawls, lo racional responde a criterios empíricos del razonamiento, mientras que lo razonable forma parte de la razón pura. De esta manera, la razonabilidad es el principio de la moralidad y la racionalidad la forma de construir y perseguir una concepción del bien. Si tomamos en cuenta el principio según el cual lo "correcto" tiene prioridad sobre lo "bueno", luego entonces, lo razonable tiene una prioridad estricta sobre lo racional ${ }^{37}$. El "sentido de la justicia" es la capacidad que tienen los agentes razonables de formar, limitar y ajustar sus concepciones del bien a los requisitos impuestos por los principios de justicia. Cuando en la "posición original" de Rawls lo racional es absorbido por lo razonable, aquel se subordina de manera absoluta a este. Esta subordinación significa que los principios de justicia acordados tienen una prioridad lexicográfica frente a cualquier concepción del bien ${ }^{38}$.

Antes de entrar en la crítica que a mi juicio genera la conjugación de estos elementos, recordemos la postura general que los liberales de esta corriente sostienen sobre la tolerancia. Según lo que vengo diciendo, los filósofos del deontologismo sostienen que el mecanismo de la tolerancia requiere: (1) que una convicción moral o una convicción

${ }^{35}$ Rawls, J., Political Liberalism, op. cit., pág. 19.

${ }^{36} \mathrm{Ibid}$., pág. 48 , nota a pie 1.

${ }^{37}$ Rawls, J., "Justice as Fairness...", op. cit., pág. 401, nota a pie 20.

${ }^{38}$ Rawls, J., "Kantian Constructivism in Moral Theory", en Samuel Freeman (ed.), op. cit., pág. 319. 
no moral (pero basada en razones) haya sido lesionada por el acto de un tercero, (2) que el agente afectado, a pesar de tener el poder o la competencia para detener u obstaculizar el acto en cuestión, (3) por determinadas razones morales decide abstenerse de actuar en contra de dicho acto. Esto, como hemos visto, implica la derogación o la moralización de la convicción lesionada.

Bajo estos términos, la tolerancia está caracterizada como la práctica de permitir deliberadamente algo que uno desaprueba o disgusta por razones morales.

Si esto es correcto, entonces, la postura deontológica se enfrenta a dos clases de conflicto: uno, cuando son reglas y/o principios morales los que han sido afectados por los actos de un tercero. Aquí el problema es profundo, pues este genera un conflicto entre un valor moral (la convicción lesionada) y otro valor del sistema justificante (las razones para la no intervención). La profundidad de este problema radica en que puede dar lugar a un genuino conflicto de valores equiparable a una situación dilemática, de la que no estoy muy seguro el deontologismo esté equipado para aceptar o para poder resolver airosamente.

El segundo conflicto se da cuando son reglas y/o principios no morales (éticos, estéticos, religiosos, ideológicos o filosóficos) los que han sido afectados y, para saber si actuamos en contra del acto que los afectó, hacemos una valoración de ellos tras el prisma de los principios morales del sistema justificante. Aquí, siguiendo el esquema deontológico, el problema encuentra su raíz en un conflicto práctico menos profundo ${ }^{39}$ que el anterior.

Digo que la contradicción entre estas dos clases de normas es menos profunda, porque, si recordamos, las razones morales del sistema justificativo son las razones últimas, es decir, que no puede haber razones que se impongan a la moral porque estas tienen prioridad sobre el resto de las normas. Si esto es así, entonces, debemos preguntarnos: ¿qué caso tiene ponerlas a "competir" o "ponderarlas" con convic-

${ }^{39} \mathrm{La}$ "profundidad" la defino en términos de la complejidad teórica que cada teoría tendría para enfrentar determinados problemas y no según las implicaciones prácticas para la vida de un agente moral. 
ciones no morales? Sobre todo, ¿qué chance tendrán estas últimas de sobrevivir en una ponderación frente a razones morales?

Ahora bien, claramente lo anterior me lleva a tratar estos problemas por separado. Primero, me detendré en el problema que he llamado "profundo". Explicaré brevemente las implicaciones de dicho problema. Esto se debe a que, aunque tiene implicaciones sumamente graves para el liberalismo deontológico, se ha dicho mucho más sobre esta clase de problemas en la literatura especializada que sobre el otro problema que he calificado de "menos profundo" 40 ; aquel generado por el conflicto que podría haber entre valores morales y otros valores no morales. Este segundo problema centrará más mi atención. Posteriormente, explicaré por qué considero que la tolerancia bajo el manto del deontologismo moral se convierte en un concepto suicida.

\section{IV.}

Es ampliamente aceptado por la comunidad filosófica contemporánea que cuando la tolerancia implica un conflicto entre dos valores morales esta se convierte en "paradójica". Es decir, que esta encarna lo que en la filosofía moral llamaríamos una "situación dilemática".

Podríamos explicar esta situación con las palabras de Raphael cuando dice que:

[d]esaprobar algo significa que lo juzgas como malo. Un juicio tal no expresa una preferencia puramente subjetiva sino que tiene una pretensión de universalidad. Pretende ser aceptado por cualquier agente racional. ¿Si nuestra desaprobación está moralmente justificada, luego entonces, por qué debemos ir en contra de ella? ¿Por qué hemos de considerar esto como algo correcto?41.

${ }^{40}$ Clasifico los problemas como "profundos" y como "menos profundos" haciendo referencia a los grados de complejidad que cada uno de ellos representa para su resolución para el deontologismo moral.

${ }^{41}$ Raphael, D.D., "The Intolerable", en Mendus, S. (ed.), Justifying Toleration. Conceptual and Historical Perspectives, Cambridge, Cambridge University Press, 1988, pág. 139. 
Podemos decir a pies juntillas de lo anterior que, en este caso, la tolerancia nos enfrenta con una situación en la que el agente se encuentra tironeado por dos requerimientos morales igualmente válidos: la convicción moral que ha sido lesionada, la cual nos obliga a actuar en contra del acto que la lesionó, y otro valor moral que nos invita a no actuar en contra de dicho acto.

Christopher W. Gogans define esta clase de situaciones dilemáticas como aquellas situaciones en las que

un agente moral $S$ está moralmente obligado a hacer $A$ y está moralmente obligado a hacer $B$ pero no puede satisfacer simultáneamente ambas obligaciones, ya sea porque $B$ implica precisamente no hacer $A$ [esto lo lleva a resultados incompatibles] o, porque algo en el mundo no le permite hacer ambas $\operatorname{cosas}^{42}$.

Otro autor que ha estudiado la naturaleza filosófica de los dilemas morales in extenso es Guillermo Lariguet. De acuerdo con Lariguet, de esta definición sugerida por Gowans se derivan ciertas consecuencias prácticas:

i) el conflicto no tiene resolución racional posible, por ejemplo porque los valores o principios contendores son considerados mutuamente inderrotables o incomparables, o ii) el conflicto podría ser resuelto eligiendo uno de los principios, pero esta elección entrañaría sacrificio o pérdida moral ${ }^{43}$.

Sin embargo, frente al tema de los dilemas morales las cosas no son nada pacíficas. Por lo pronto, debemos tener en mente que hay filósofos que defienden la idea según la cual si las teorías morales tienen como propósito principal el guiar la conducta de los individuos, estas deben estar libres de dilemas. En cambio, otros consideran que una buena teo-

${ }^{42}$ Gowans, C.W., "Intoduction. The Debate on Moral Dilemmas", en C. W. Gowans (ed.), Moral Dilemmas, Nueva York, Oxford University Press, 1987, pág. 3. ${ }^{43}$ Lariguet, G., "Conflictos trágicos y derecho. Posibles desafíos", Doxa. Cuadernos de Filosofia del Derecho, 27, 2004, págs. 318-319. 
ría moral debe reconocer la existencia de esta clase de conflictos, precisamente, para poder encontrar vías plausibles de solución.

En este sentido, el deontologismo moral comúnmente se relaciona con la primera postura. Es de sobra conocido que las teorías morales de corte deontologista sostienen que los dilemas morales son una especie de "déficit epistémico" que sufren los agentes cuando sostienen encontrarse en una situación dilemática. De hecho, esta clase de filósofos diría que cualquier persona que piense estar en una situación de este tipo es porque en realidad o no ha hecho un diagnóstico correcto de la situación en la que se encuentra o tiene un problema de consistencia sistémica que debe resolverse a través de las leyes de la lógica. Esto es, un dilema es o un error de apreciación o un problema lógico.

En este sentido, como ha sostenido Lariguet, la filosofía kantiana se ha acorazado en dos principios lógicos que le permiten rechazar la existencia de esta clase de situaciones: (I) "debe implica puede", y (II) "el principio de aglomeración y conjunción" 44 . Siguiendo el primero de estos principios, los kantianos aseguran que si una persona está obligada a hacer $A$ y está obligada a hacer $B$, pero por determinadas razones no puede realizar una de estas obligaciones, luego entonces, no está obligada a realizarla. Según el segundo de los principios, dirán que si sí está obligada a realizar $A$ y $B$, luego entonces, está obligada a realizar ambas cosas (OA \& OB).

Además de estos dos principios mencionados, el deontologismo moral también rechaza la existencia de esta clase de conflictos basándose en otros dos presupuestos filosóficos que terminan por reforzar su armadura. El primero es un presupuesto epistémico relacionado con la forma en que ellos idealizan los sistemas normativos. Los sistemas normativos de corte deontológico están construidos bajo (III) la idea de la consistencia. Este presupuesto no solo se refiere a la idea de sistemas normativos completos, sino también a sistemas que rechazan la idea de reglas o principios inconsistentes (contradictorios) ${ }^{45}$. E1 segundo presu-

${ }^{44}$ Lariguet, G., Dilemas y conflictos trágicos. Una investigación conceptual, LimaBogota, Temis-Palestra, 2008, pág. 61 y ss.

${ }^{45}$ Alchourrón, C. y Bulygin, E., Introducción a la metodología de las ciencias jurídicas y sociales, Astrea, Buenos Aires, 1987, Capítulo X. 
puesto es de corte normativo y está relacionado con el ya conocido principio que dicta la (IV) "prioridad de lo correcto sobre lo bueno".

Tomando todos estos criterios en consideración, entonces, podremos decir que el deontologismo moral defiende las siguientes tesis:

1. Actuar correctamente significa actuar conforme a las obligaciones morales. Considera que estas obligaciones son autoimpuestas (autónomamente aceptadas) y razonablemente creadas (sin considerar razones relativas al agente).

2. Obedecer las normas morales no implica considerar las consecuencias (benéficas o perjudiciales) de nuestros actos.

3. Los sistemas normativos tienen que ser completos y consistentes. Esta consideración los lleva a sostener sistemas normativos monistas que evitan problemas de incoherencias e inconsistencias.

4. Las normas morales son inderrotables. Si queremos actuar moralmente, luego entonces, no puede haber ninguna otra consideración, valor o principio distinto a la moral y que derrote las normas que pertenecen a ese ámbito. Los agentes morales están categóricamente vinculados a las normas morales.

Con estos rasgos en nuestras manos, ahora podemos ver con mayor facilidad cuáles son los elementos que estos autores usan para defender la idea de que los dilemas morales son el producto de "sistemas patológicos" o de "déficits epistémicos".

Recuérdese que para los autores que hemos analizado anteriormente, el rationale que proveen para la tolerancia consiste en lo siguiente: cuando una norma de un sistema normativo básico (SNB) ha sido lesionada tenemos que ponerla bajo el escrutinio crítico del sistema justificante moral (SJM). Pero cuando dos normas que tienen el mismo valor moral, es decir, dos normas que en estricto sentido deberían o pertenecen al SJM, el procedimiento claudica, pues no encuentra respuesta en el desdoblamiento sistémico que propone dado el conflicto entre normas de un mismo rango normativo. Y por razones de carácter lógico la única respuesta que encuentra es que una de las normas en conflicto debe ser incorrecta o inválida desde un punto de vista moral. En esos casos deberá salir del sistema justificante. 
Si esta es la manera en que dichos autores resuelven las situaciones prácticas que involucran actos de tolerancia, entonces, podríamos decir que el énfasis sigue siendo una cuestión de "consistencia" lógica. Adviértase que esta solución pretende prevenir la disyuntiva de tener que escoger entre dos normas morales contradictorias que se consideran relevantes. En estos casos, el deontologismo moral trata de prevenir que los agentes morales experimenten una sensación de vértigo producido por la incapacidad lógica de su sistema normativo para servir como una confiable guía de conducta ${ }^{46}$.

Empero, hasta qué grado la estrategia deontológica elimina la posibilidad de vértigo que la tolerancia puede llegar a presentar es algo de lo que no estoy muy seguro. Autores como Bernard Williams dirían que la solución de derogar una de las normas en pugna no es solución alguna para evitar dicha clase de vértigo. Al contrario, derogar una norma que considerábamos relevante para vivir nuestras vidas, que ha dado sentido a nuestra existencia, o que simplemente la pensábamos como importante, puede dejar una especie de residuo moral coincidente con la sensación de vértigo ${ }^{47}$. Es decir, que una decisión como esa puede estar acompañada de sentimientos de culpa o de remordimiento; sentimientos que nos dicen que, cualesquiera que sean las razones por las que hicimos lo que hicimos, hemos hecho mal. En estos casos: o la tolerancia se convierte en un vicio moral o, simplemente, en una virtud imposible de lograr.

\section{V.}

Aún así, podemos pensar que el liberalismo deontológico no tiene intención alguna de aplicar el mecanismo de la tolerancia para conflictos

${ }^{46}$ Esta sensación de "vértigo moral", cuando nuestros sistemas normativos dan de sí, ha sido resaltada por Guillermo Lariguet, quien a su vez, parafrasea a Stanley Cavell. Lariguet, G., "Conflictos trágicos genuinos, ponderación y límites de la racionalidad jurídica. En torno a algunas ideas de Manuel Atienza", Isonomía. Revista de Teoría y Filosofia del Derecho, 24, 2006, pág. 102. Ensayos filosóficos 1973-1980, Ciudad de México, IIF-UNAM, 1993, pág. 98. 
entre normas morales porque estas tienden a ser consistentes entre sí. Entonces, la tolerancia consistiría básicamente en el conflicto potencial entre convicciones del Sistema Normativo Básico y las normas morales del Sistema Justificativo Moral. Empero, en esos casos iqué sucede con las convicciones éticas, estéticas, filosóficas, ideológicas, religiosas, y demás clase de convicciones que un individuo puede defender? ¿Qué oportunidad les estamos dando para sobrevivir dentro de nuestros sistemas normativos si las ponemos a competir con las normas morales? Debemos notar también que si nos tomamos la ponderación de razones en serio, es porque implícitamente estamos considerando que realmente puede existir una clase de conflicto entre valores no morales (o subjetivos) $)^{48}$ y normas morales con carácter universal.

Con esto en mente tenemos que preguntarnos: ¿qué clase de conclusión normativa se puede derivar de una ponderación intersistémica como la sugerida por el liberalismo deontológico? ¿Acaso una deliberación que involucre una convicción estética o de la moda y una norma moral puede arrojar como resultado la obligación moral de vestir bien?

Pensemos en este ejemplo: un acto que recurrentemente viola una prohibición de nuestro sistema normativo estético. Lo primero que debemos preguntarnos es qué tan relevante puede ser cometer algo así como un crimen de moda bajo la perspectiva de la moral. Y lo que después debemos preguntarnos es si cobra algún sentido hablar de una ponde-

${ }^{48}$ Las normas o valores que he calificado como subjetivos se entienden como aquellas que están basadas en criterios racionales pero que solo sirven para guiar nuestra propia vida. Estas responden a preguntas relacionados con lo que es bueno "para mí" y lo que es correcto "para nosotros". Por lo tanto, no operan como guías universales de conducta. Las normas morales, tal y como las ha definido el deontologismo liberal, son aquellas que parten de una posición de imparcialidad, reclaman validez universal y requieren de métodos de justificación distintos a estos otros valores "personales". Rainer Forst, por ejemplo, marca la misma diferencia entre valores éticos y normas morales. Forst dice que los valores éticos pueden estar justificados de una forma tridimensional: la subjetiva, la intersubjetiva y la objetiva. Aún así, no pueden ser considerados como generales y categóricos en el sentido que se entienden las normas morales. Forst, R., "Ethics and Morality", en Forst, R., The Right to, op. cit., pág. 65. 
ración entre esta prohibición estética y las normas morales del sistema justificante. Y, si puede haber una ponderación, cómo funcionaría.

Posiblemente, los deontologistas pueden aceptar que esto sea posible o que esto cobre sentido de algún modo. Pero aún así, durante la ponderación de valores terminaríamos por preguntarnos sobre la clase de conflicto que podría generar una colisión de esta naturaleza. ¿Bajo el prisma moral del deontologismo liberal, en realidad, tendremos algún problema para decidir sobre cuál de las dos normas en conflicto tiene prioridad? Sobre todo, si recordamos que este esquema de racionalidad práctica asume como regla la prioridad o la supremacía de las normas morales por sobre todas las demás. En esos casos, e independientemente de que nuestra convicción esté subjetiva, o intersubjetiva, $\mathrm{u}$ objetivamente justificada y sea considerada como relevante para el sujeto de tolerancia, esta no es considerada moral.

Es importante que no perdamos vista que aunque un acto de tolerancia se inicia a causa del acto de un tercero, lo que nos interesa en este momento es el conflicto práctico que enfrenta el sujeto de tolerancia. Es decir, no me interesa ahora el conflicto que involucra varios participantes sino el que involucra a un solo participante: el sujeto de tolerancia. Este conflicto al que se enfrenta este individuo, causado sin duda por el acto de un tercero, sostiene dos normas que se contradicen: una que le dice que debe actuar en contra de la acción $X$ (la objeción) y otra que le dice que no debe actuar en contra de $X$.

Supongamos el caso de un profesor universitario que siempre está preocupado por ir bien vestido, es una persona muy elegante, y debido a esta clase de gustos estéticos, le desagradan, profundamente, las camisas con holanes. Fundamentalmente, porque esta clase de camisas están pasadas de moda, porque cree que no son elegantes, o porque cree que a la gente le sientan mal. Y ahora está en una encrucijada: lo invitaron a una cena de la facultad y su esposa usará una camisa con holanes que acaba de comprar. Aquí, el deontologismo sugeriría que si quiere tolerar este acto debe someter su prohibición al juicio de su sistema justificante. Esto es, al escrutinio crítico de las normas morales. O sea, debe preguntarse si es moralmente correcto prohibirle a su esposa (y a todos aquellos que caigan bajo el mismo supuesto) que use esa clase de camisas. 
Dejando a un lado el hecho de que no creo que el profesor tenga la competencia (entendida como una subclase de la autoridad moral) que le permita prohibirle a su esposa (o a cualquier otra persona) usar esta clase de camisas (que ya es un problema grave frente a estos casos por la seria falta de racionalidad al querer algo que uno sabe no puede lograr, por un lado, y la incapacidad de poder imponer legítimamente a otras personas nuestros gustos personales, por el otro), no alcanzo a ver cuál sería la conclusión que derivaría de un escrutinio como este.

Digamos que en caso de que resolviera "tolerar" que su esposa vaya "mal" vestida, lo sería según el esquema de justificación propuesto, porque tras ponderar su regla de la moda con algún principio moral, se dio cuenta de que es moralmente obligatorio dejar que otras personas se vistan como a él no le gusta. $\mathrm{O}$, en caso de que resuelva "no tolerar" la camisa de su esposa, sería porque cree que es legítimo pensar que hay un deber (un deber moral) para vestirse de cierta manera.

Si dejamos las cosas en el plano de la moda, ambas conclusiones me parecen contraintuitivas, por decir lo menos. No veo la manera en que pueda entrar en "conflicto" la regla de "prohibidas las comisas con holanes por su bajo sentido estético" con algún otro principio moral de mi sistema justificante. Esto es, no encuentro contradicción entre las razones que subyacen a esta regla y las razones últimas de otra norma moral.

Aún más, bajo este tenor no veo la posibilidad de que efectivamente exista una ponderación de valores y, sobre todo, de que pueda derivarse lógicamente de ella una regla que nos prescriba el "deber moral de vestirnos bien"; que, además, fuera del problema de qué significa "vestirnos bien" o de cómo se decidiría una cosa como tal, es una conclusión de corte moral que pocos estaríamos dispuestos a aceptar.

Es claro, entonces, que el meollo del asunto está en si realmente es relevante incluir este tipo de reglas en el ámbito de la tolerancia; si es apropiado hablar de tolerancia en estos casos, pues si no lo es, la tolerancia quedaría reducida, como ha argumentado Peter Nicholson, a cuestiones relacionadas con normas morales. Pero en ese caso, la tolerancia quedaría enfrascada en la inmensa dificultad que he argumentado en el parágrafo anterior. 
Ciertamente, para pensar que uno puede legítimamente (justificadamente) restringir la libertad de otro se requiere de algo más que pensar que lo que esa persona hace, piensa o usa nos disgusta, que es de mal tino o, que no es lindo. Se tienen que aportar razones que justifiquen nuestra intervención. Esto es conicidente, hasta cierto grado, con los que autores como Garzón y Forst afirman. Para ellos no basta con la apelación a mi propia creencia de que $p$ es verdadero para que $p$ pueda ser aceptado como razón justificativa ${ }^{49}$.

En sintonía con estos autores, Richard Hare diría que si el profesor en realidad cree estar en un conflicto, lo que tiene que hacer, en lugar de ponderar estas dos reglas y arribar a un "monstruoso principio híbrido que ni es moral ni es estético ni es nada" ${ }^{50}$, es dejar su principio estético a un lado y actuar en favor del principio moral. Esto es, rechazar o aceptar, mas no tolerar. Adoptar una postura más condescendiente frente a los gustos de otros porque no puedo justificadamente imponerle los míos, aunque sea algo sumamente deseable. Al decir esto, repárese que cuando no hay razones que soporten nuestro reclamo se distingue entre la condescendencia y la tolerancia que, por definición, no son lo mismo.

Garzón argumentaría que el principio estético se tiene que derogar o se tiene que reafirmar, y que este proceso implica, a su vez, la moralización del sistema al que pertenece dicho principio. Nótese que, debido a la defensa que estos autores hacen de la "unidad de la razón práctica", rechazan la idea de que cada esfera normativa cuente con sus propios criterios de justificación. Con este criterio se asumen dos implicaciones prácticas que me parecen contraintuitivas: o la moralización de nuestros gustos y de nuestras preferencias personales, o declarar como triviales nuestras concepciones no morales.

En estos casos coincido con las tesis sostenidas por algunos autores, como Bernard Williams por ejemplo, de que si la gente realmente sometiera cada una de sus normas estéticas al escrutinio moral cada

${ }^{49}$ Garzón Valdés, E., "El sentido actual de la tolerancia", en Alexy, R., Teoría del discurso y derechos constitucionales, Cátedra Ernesto Garzón Valdés, Ciudad de México, Fontamara, 2004, pág. 15. 
vez que alguien comete un acto que va en contra de ellas, no solo viviríamos en una especie de infierno moral, sino que, además, nuestros sistemas normativos serían una mezcla inteligible de reglas híbridas sin sentido práctico alguno ${ }^{51}$.

Se podría decir que he dejado las cosas en el plano de la moda y de reglas estéticas que poca relevancia pueden tener bajo el prisma de la moral y que he dejado de lado otras cuestiones también importantes, o más importantes, como por ejemplo las consideraciones éticas. Por ello, debemos considerar qué pasa en un caso de conflicto con esa clase de valores. A diferencia de los valores estéticos y de la moda que tan solo usé como ejemplo, los valores éticos tendrán alguna oportunidad de sobrevivir el escrutinio moral del sistema justificante.

Rainer Forst ha discutido esta cuestión con cierto detalle. Para Forst, los conflictos entre valores éticos y normas morales son sin duda posibles. En su Ehtics and Morality, Forst considera que problemas como el aborto, la eutanasia o la manipulación genética son un claro ejemplo de esta clase de problemas. Más allá de la dificultad que muchos filósofos encuentran para resolver esta clase de problemas, su postura frente a ellos es bastante clara. Forst asegura que

en dichos casos hay un claro acuerdo en que los argumentos morales pesan mucho más que los derivados de la ética. Y con la ayuda de los criterios formales que sostienen al argumento moral se puede examinar concretamente la justificabilidad de los reclamos [éticos] de cada uno de los participantes ${ }^{52}$.

La tesis que defiende Forst es que dentro de las deliberaciones prácticas de un solo agente las distintas dimensiones normativas - la ética y la moral en este caso- deben conjugarse en una sola. Como

${ }^{51}$ Williams, B., afirma que "algunas veces nos guía la idea de que el mejor de los mundos sería aquél en que la moralidad se respetara universalmente y todas las personas estuvieran dispuestas a avalarla, en realidad tenemos razones profundas y persistentes para agradecer que nuestro mundo no sea así", Williams, B., La fortuna moral, op. cit., pág. 38.

${ }^{52}$ Forst, R., "Ethics and...", op. cit., pág. 68. Los corchetes son míos. 
he sostenido antes, esta perspectiva representa uno de los elementos característicos del liberalismo deontológico: la unidad de la razón práctica. Carlos S. Nino, otro liberal deontológico de alta prosapia, explica esta unidad diciendo que: "el discurso moral no cumpliría su función de conducir a comportamientos convergentes si los principios de conducta que resulten aceptados a través de él, no tuvieran una cierta jerarquía frente a otras posibles razones para actuar" ${ }^{53}$, tales como las razones prudenciales o las creencias religiosas. Esta otra clase de razones y de valores pueden justificar acciones cuando no hay consideraciones morales en juego. Tan pronto entren consideraciones morales en el terreno deliberativo, ninguna otra clase de razones puede proveer criterios de justificación. Cualquier filósofo que se adhiera a la "unidad de la razón práctica" estará de acuerdo con la tesis de que existe un orden jerárquico en la razón práctica.

Si tomamos en consideración todo lo anterior, en el caso de que la tolerancia implique un conflicto entre valores éticos y normas morales, solo existen cuatro soluciones lógicas posibles, que son las que anuncian una muerte prematura para el ideal moral:

a) Ya sea que la norma del SNB prescriba que en la circunstancia A, $p$ es el caso, y el SJM, al contrario, estipule que $\sim p$. En tal caso, por una cuestión de superioridad del SJM, $p$ es derogado.

b) Ya sea que la norma del SNB diga que en la circunstancia A $\sim p$, y el SJM prescriba lo contrario, es decir, $p$. Por lo tanto, la norma que dicta $\sim p$ es derogada.

c) Ya sea que la norma del SNB diga que en la circunstancia A, $p$ es el caso, y el SJM confirme la prescripción. En ese caso, la norma del SNB se confirma y se moraliza.

d) Ya sea que la norma del SNB diga que en la circunstancia A, no es el caso que $p$, y el SJM confirme dicha negación. En ese caso, la norma también se confirma y el sistema se moraliza.

Sea cual fuere la decisión, el quid de la cuestión está en que, apa-

${ }^{53}$ Nino, C.S., Ética y derechos humanos. Un ensayo de fundamentación, Buenos Áires, Editorial Astrea, 2005, pág. 111. 
rentemente bajo el esquema deontologista, la tolerancia no solo no levanta situaciones dilemáticas, sino que implicaría ser un proceso de limpieza sistémica y no un proceso deliberativo mediante el cual, en determinadas circunstancias, detenemos la fuerza normativa de una convicción que consideramos válida e importante para vivir la vida que consideramos merece la pena ser vivida.

Es decir, según lo que vengo diciendo, para el liberalismo deontológico la tolerancia juega el papel de un proceso mediante el cual se pone en consideración la posible derogación o la posible confirmación moral de las normas que forman parte de los distintos sistemas normativos básicos (éticos, estéticos, ideológicos, religiosos, etc.). Y no se trata de un proceso mediante el cual un agente decide no aplicar (que no es lo mismo que derogar o moralizar) una norma que considera válida en determinadas circunstancias y seguir considerándola válida. En una frase, para el dentologismo la tolerancia es un proceso moral que censura el contenido de los sistemas normativos básicos derogándolos o asimilándolos al sistema moral, lo que deriva en que estos tienen fecha de caducidad definida, esto en razón de la finitud que tienen los sistemas normativos de los individuos. Si las convicciones son finitas, los casos de tolerancia también lo son. Esto nos lleva a pensar que la tolerancia es una cuestión pasajera y no una virtud práctica que es puesta a prueba en reiteradas ocasiones ${ }^{54}$.

Si seguimos las líneas marcadas por esta concepción del razonamiento práctico y la critica que vengo armando, entonces, la tolerancia se vuele o irrelevante o recalcitrante. Se vuelve irrelevante en dos situaciones distintas: primero, porque si la convicción, que pensábamos que era un valor ético o religioso o ideológico resulta que, después del escrutinio crítico, en realidad estaba también moralmente justificada, entonces, ya no existiría ningún impedimento para imponérsela a otros. Y segundo, la tolerancia se vuelve irrelevante porque si el valor ético (o religioso o ideológico) resulta ser moralmente incorrecto, bajo el prisma deontológico, lo que tenemos que hacer es eliminarlo de nuestro sistema de valores; en ese caso, en el momento en que mi objeción no moral

${ }^{54}$ Garzón Valdés, E., “'No pongas tu sucias manos sobre...”, op. cit., pág. 181. 
desaparece dejo de tener bases para hablar de tolerancia.

La tolerancia se vuelve recalcitrante cuando involucra dos valores igualmente válidos desde un punto de vista moral que sostienen tanto la aceptación como el rechazo del acto que objetamos. Este es el conflicto que he analizado anteriormente sobre las situaciones dilemáticas.

De las dos causas de irrelevancia antes mencionada se deriva un tercer tipo de problema: la propensión suicida de la tolerancia.

\section{VI.}

Al inicio de este trabajo he afirmado que la tolerancia entendida como un ideal moral en las manos del liberalismo deontológico se vuelve "suicida". Lo anterior es solamente el corolario de una crónica que anuncia la muerte de la tolerancia a manos del deontologismo.

Aquí el término "suicida" requiere de una explicación. Como la requeriría cualquier otro uso metafórico del lenguaje en un discurso filosófico. Cuando las metáforas no son entendidas en un sentido 'literal' sino en un sentido figurado, suelen brindar luz a nuestro argumento en vez de opacarlo. Por ejemplo, como cuando Mario, el personaje principal de Ardiente Paciencia ${ }^{55}$ de Antonio Skármeta, le dice a Neruda que la sonrisa de Beatriz (su amor platónico) es como una mariposa. Si esta expresión es tomada literalmente nos llevaría a pensar que Beatriz es una mujer deforme que no merecería la atención de Mario. Sin embargo, cuando la entendemos en sentido figurado la metáfora describe una encantadora y juguetona sonrisa difícil de resistir. Las metáforas tomadas de esta forma son extensiones del pensamiento que pueden satisfacer las necesidades de un orador cuando quiere ir más allá del mero uso descriptivo del lenguaje. De esta forma, las metáforas deben entenderse como complementos lingüísticos y no como decoraciones superfluas del pensamiento. En su The Sovereingnty of Good, Iris Murdoch defiende el uso de las metáforas dentro del discurso filosófico diciendo que no

${ }^{55}$ Como muchos recordarán esta novela más tarde fue llevada a la gran pantalla bajo la dirección de Michael Radford y bajo el título de Il Postino. 
solo son permisibles sino que son necesarias ${ }^{56}$.

Es en ese sentido metafórico en que uso el término "suicida" y no de manera descriptiva o literal. Básicamente, lo que trato de expresar a través de este término es otra paradoja más que encierra la tolerancia cuando se encuentra en manos del liberalismo deontológico.

En 1993 Pablo Navarro publicó un texto titulado Reflexiones sobre el concepto de tolerancia ${ }^{57}$. Allí Navarro criticó varias partes de la propuesta conceptual de Ernesto Garzón, en particular, las que, a mí parecer, se expanden a todo el panorama de teorías que comparten el mismo esquema de razonamiento. Entre las cosas que Navarro criticó en aquella ocasión, hay una que es la que me interesa retomar aquí. La que se podría denominar como "el problema de la cronología de la tolerancia".

Según Navarro, la formula triádica sobre la que descansa la tolerancia en el deontologismo liberal, según la cual $a T b X c, t 1$, implica que $P h$ $X$ en $C n S b a$ (t0), no refleja la noción de conflicto que hemos analizado entre el sistema básico y el sistema justificante. Para dar cuenta de ello Navarro simboliza esta situación de la siguiente manera:

$$
\text { aTbXc, } \mathrm{t} 1 \rightarrow \mathrm{PhX} \in \mathrm{CnSba}(\mathrm{t} 0) \& \mathrm{PX} \in \mathrm{CnSba}(\mathrm{t} 2)
$$

Esto es, antes del acto de tolerancia, en t0, el acto se encontraba prohibido en el sistema básico, tras tolerar dicho acto, ahora, en t2 el mismo acto se encuentra permitido. Esto genera, según Navarro que la

cronología de la tolerancia se resume de la siguiente manera: en el momento t0 está prohibido X en el $\mathrm{Sb}$ de $a$, en el momento t1 $a$ tolera $\mathrm{X}$ y esto resulta en la derogación de la prohibición de $\mathrm{X}$ en $\mathrm{Sb}$ a partir de $\mathrm{t} 1$. Si el resultado de la derogación de una prohibición es una norma permisiva o permisión expresa entonces $b$ adquiere un derecho a X y no cabría — a partir de t1 $+\mathrm{n}$ - afirmar que $a$ tolera $\mathrm{X}^{58}$.

${ }^{56}$ Murdoch, I., The Sovereignty of Good, Londres, Routledge Classics, 2002, pág. 75.

${ }^{57}$ Navarro, P.E., "Reflexiones acerca del concepto de tolerancia", Doxa, 13, 1993.

${ }^{58}$ Navarro, P.E., "Reflexiones acerca del concepto de tolerancia”, op. cit., pág. 280. 
Es decir, la tolerancia se agota en un solo acto. Si alguien decide tolerar algo el lunes, según este esquema, ya no puede decir que lo tolera el martes. Si esto sucede, el enunciado que dice que alguien tolera todas las veces que toma lugar el acto $X$, ya no podría ser verdadero. Pues el actor de $X$, de acuerdo con este esquema, habría adquirido un permiso débil o un derecho. Y, como se sabe, no cabe hablar de tolerancia frente a cosas que permitimos o alabamos.

En suma, cada acto de tolerancia es un paso al frente que se refuerza el círculo de intolerancias. Por ello, es posible afirmar que bajo el prisma del deontologismo liberal el ideal de la tolerancia es una virtud pasajera, contraria a la idea de ser una "propiedad disposicional" de los agentes morales. Entre menos tolerancia, mayor homogeneidad. La tolerancia, en algún sentido, es tomada como la medicina que paulatinamente curará el "hecho" del pluralismo moral.

\section{VII.}

La idea general que he defendido a lo largo de estas páginas consiste en que la tolerancia entendida como ideal moral es incompatible con los requerimientos lógicos que impone la estructura deontológica del razonamiento práctico. Esto lo he defendido a través de tres argumentos:

1. El primer argumento estaba dirigido a denunciar los problemas que el deontologismo moral tiene al enfrentar el dilema moral de la tolerancia. En ese caso argumenté que los defensores del deontologismo sufren de dos incapacidades: a) rechazan la idea general sobre la existencia de los dilemas morales. Por ello, para estos autores la "paradoja de la tolerancia" o el "dilema de la tolerancia" solo representa un escenario construido por "filósofos de gabinete" que hace referencia a una situación de clara deficiencia epistémica, y b) cuando algunos filósofos kantianos aceptan la existencia de dilemas morales, normalmente obvian el carácter trágico que esta clase de problemas puede generar. Me refiero, específicamente, a la pérdida o el sacrificio que se generan al resolver un conflicto de esta naturaleza. Per- 
der de vista esto implicaría que no tomamos en consideración que resolver el dilema de la tolerancia equivaldría a tener que desechar un valor o una norma que consideramos de irremplazable trascendencia en nuestras vidas. Por tanto, tolerar podría tornarse en una conducta irracional de los individuos.

2. El segundo de ellos sostiene que la estructura del razonamiento práctico defendida por el deontologismo moral es indiferente al valor que los individuos le atribuyen a sus creencias éticas y a sus concepciones del bien. El peso normativo que los filósofos del deontologismo dan a las normas morales universales es tan fuerte que logra remover cualquier criterio de relevancia que los valores éticos puedan llegar a tener dentro de nuestras deliberaciones prácticas.

3. El último de los argumentos presentados hace referencia a las tensiones creadas por los requerimientos conceptuales de la tolerancia y los del deontologismo. He defendido que los principios básicos de esta estructura del razonamiento y la forma en que el deontologismo concibe las normas morales hacen de la tolerancia un "concepto suicida". Esta tensión se debía, entre otras cosas que se pueden argumentar, a la distinción que el deontologismo hace entre varias esferas normativas. Específicamente, entre la "ética" y la "moral". También se debe al carácter no condicional de las normas morales.

Esta incompatibilidad entre el deontologismo liberal y el ideal moral de la tolerancia se debe, entre otras cosas, a la concepción "legalista" o "formal" que el deontologismo sostiene sobre la moral. En 1958, Elizabeth Anscombe llamó legalistas a todas aquellas teorías morales que estaban preocupadas por encapsular las consideraciones éticas (las concepciones del bien) dentro del criterio de universalidad ${ }^{59}$. Esta preocupación se tradujo en una concepción sumamente reducida del mundo práctico perdiendo de vista su basto universo.

Un filósofo como Williams, que defiende de cerca esta postura fi-

${ }^{59}$ Anscombe, G. E. M. , "Modern Moral Philosophy", Philosophy, 33, 124, 1958, págs. 12-13. 
losófica à la Anscombe, diría que esta forma de entender la moral olvida que las consideraciones éticas son mucho más complejas y mucho más ricas de lo que estas teorías están dispuestas a aceptar. La ética comprende cuestiones relacionadas con la amistad, la familia, la sociedad, los intereses y los deseos personales, cuestiones que deberían ocupar un lugar especial en nuestras teorías morales ${ }^{60}$.

Si la tolerancia ha de entenderse como una virtud, esto significa que la tolerancia requiere más de criterios como la percepción, la inclinación o la motivación y el reconocimiento de las particularidades de cada caso en concreto, que de la idea de una aplicación coherente, consistente e inapelable de reglas preconcebidas.

Esto tiene que ver con otra de las razones que tengo para argumentar la incompatibilidad a la que me he venido refiriendo. Rainer Forst ha defendido la idea de que la tolerancia es un concepto normativamente dependiente. Lo que Forst defiende al decir esto es que la tolerancia es un concepto sustancialmente vacuo, que tiene que ser rellenado a través de una concepción específica de la justicia, la cual tiene que ir de la mano con una noción del razonamiento práctico ${ }^{61}$. Coincido con Forst en la vacuidad del concepto de tolerancia y en la idea de que este debe ser soportado por una concepción de la justicia y del razonamiento práctico. Sin embargo, es importante notar que decir que la tolerancia es un concepto normativamente dependiente no implica que, necesariamente, la tolerancia pueda ser "rellenada" o "soportada" por cualquier concepción de la justicia y por cualquier noción del razonamiento práctico. Esto es, la vacuidad del concepto de tolerancia no la hace compatible con cualquier concepción del razonamiento moral.

La incompatibilidad de la tolerancia con una noción deontológica del razonamiento práctico se debe a que la tolerancia es un concepto ético según el cual no solo es normativamente dependiente sino que también es un concepto contextualmente dependiente. Lo que significa que cada acto de tolerancia tiene que ser evaluado a partir de las circuns-

${ }^{60}$ Williams, B., Morality: an Introduction to Ethics, Cambridge, Cambridge University Press, 1993, págs. 68-69. 
tancias que lo provocaron y de las características particulares de cada caso en concreto. Vista la tolerancia de esta manera, difícilmente podrá ser compaginada con una concepción legalista de la moral, según la cual: las normas morales son (i) universales (aplican de igual manera a todas las circunstancias que comparten las mismas características generales), (ii) son aceptadas y configuradas apriorísticamente (su validez y criterios de justificación son aceptados previamente a cualquier contexto de aplicación) e, iii) imparcialmente justificadas (sin tomar en cuenta razones relativas al agente).

La tolerancia, como he dicho, es una virtud que requiere de una concepción del razonamiento práctico lo suficientemente sensible como para valorar adecuadamente los elementos específicos y particulares de cada contexto o circunstancia en la que es reclamada. En este sentido, la tolerancia para ser adecuadamente (justificadamente) practicada requiere de agentes morales que hayan desarrollado una sabiduría práctica (más cercana a la phronesis aristotélica que a la aplicación sistemática de reglas kantiana), que les permita afrontar los problemas morales con una aptitud más flexible. Diría, entonces, que la tolerancia debe ser compaginada con teorías morales centradas en el agente, más que en teorías morales centradas en los actos.

Es en ese sentido en que la tolerancia y el legalismo moral son incompatibles: cuando la noción de reglas como pautas que determinan categóricamente la corrección de nuestras acciones entra por la puerta, la posibilidad de que la tolerancia sobreviva sale por la ventana.

\section{Bibliografía}

Alchourrón, C. y Bulygin, E., Introducción a la Metodología de las Ciencias Jurídicas y Sociales, Buenos Aires, Astrea, 1987.

Anscombe, G. E. M., "Modern Moral Philosophy", Philosophy, 33, 124, 1958, págs. 1-19.

Camps, V., "Pluralismo y Tolerancia", Bermudo Ávila, J. (ed.) Retos de la Razón Práctica, Universidad de Barcelona, España, 2002, págs. 55-64 Cohen, A. J., "What Toleration Is?" Ethics, 115, 1, 2004, págs. 68-95. 
Dworkin, R., Justice for Hedgehogs, Cambridge, The Belknap Press of Harvard University Press, 2011.

Forst R., "Toleration, Justice and Reason", McKinnon, C. y Castiglione, D. (ed.),, The Culture of Toleration in Diverse Societies. Reasonable Tolerance, Manchester, Manchester University Press, 2003, págs. 71-85.

Forst, R., Toleration in Conflict. Past and Present, Cambridge, Cambridge University Press, 2013.

Forst, R., The Right to Justification. Elements of a Constructivist Theory of Justice, Nueva York, Columbia University Press, 2007.

Fraser, N., "Recognition without ethics?", en McKinnon, C. y Castiglione, D. (ed.), The Culture of Toleration in Diverse Societies. Reasonable Tolerance, Manchester, Manchester University Press, 2003, págs. 86-108.

Garzón Valdés, E., "El sentido actual de la tolerancia", en Alexy, R.,

Teoría del discurso y derechos constitucionales, Ciudad de México, Fontamara, 2004.

Garzón Valdéz, E., "¿Puede la razonabilidad ser un criterio de corrección moral?", en Instituciones Suicidas. Ensayos de Ética y Política, Paidós-UNAM, México, 2000.

Garzón Valdés, E., "¿Puede la razonabilidad ser un criterio de corrección moral?", en Garzón Valdés, E., Instituciones Suicidas. Ensayos de Ética y Politica, Ciudad de México, Paidós-UNAM, 2000.

González De La Vega, R., "Desacuerdos en el concepto de tolerancia", Jurídica. Anuario del Departamento de Derecho de la Universidad Iberoamericana, 37, 2007, págs. 373-393

Gowans, C. W., "Introduction. The Debate on Moral Dilemas", en Gowans, C.W., (ed.), Moral Dilemmas, Oxford University Press, 1987. Gray, J., Two Faces of Liberalism, Nueva York, The New Press, 2000. Hare, R. M., Freedom and Reason, Oxford, Clarendon Press, 1963. Heyd, D., "Introduction", en Heyd, D. (ed.), Toleration. An Elusive Virtue, Princeton University Press, 1998, págs. 3-17.

Heysse, T. y Segaert, B., "Perplexities of Tolerance", Bijdragen. International Journal in Philosophy and Theology, 71, 4, 2010, págs. 351-357

Heysse, T., "Toleration and Political Conflict. A comment on Rainer Forst's Analysis of Toleration", Bijdragen. International Journal in Philosophy and Theology, 7, 4, 2010, págs. 391-406. 
Lariguet, G., "Conflictos trágicos y derecho. Posibles desafíos", Doxa, 27, 2004, págs. 317-348.

Lariguet, G., Dilemas y Conflictos Trágicos. Una Investigación Conceptual, Lima-Bogota, Temis-Palestra, 2008.

Lariguet, G., "Conflictos trágicos genuinos, ponderación y límites de la racionalidad jurídica. En torno a algunas ideas de Manuel Atienza", Isonomía. Revista de Teoría y Filosofia del Derecho, 24, 2006, págs. 93-113.

Larmore, C., Patterns of Moral Complexity, Cambridge, Cambridge University Press, 1987.

Murdoch, I., The Sovereignty of Good, Londres, Routledge Classics, 2002.

Navarro, P., "Reflexiones acerca del concepto de tolerancia", Doxa, 13, 1993, págs. 277-284.

Newey, G., Virtue, Reason and Toleration. The Place of Toleration in Ethical and Political Philosophy, Edimburgo, Edinburgh University Press, 1999.

Nicholson, P., "Toleration as a Moral Ideal", en Horton, J. y Mendus, S. (ed.), Aspects of Toleration. Philosophical Studies, London/New York, Methuen, 1985, págs. 158-173.

Nino, C. S., Ética y derechos humanos. Un ensayo de fundamentación, Buenos Aires, Editorial Astrea, 2005.

Pettit, P., "Consequentialism and Respect for Persons", Ethics, 100, 1, 1989, págs. 116-126.

Raphael, D.D., "The Intolerable", en Mendus, S. (ed.), Justifying Toleration. Conceptual and Historical Perspectives, Cambridge, Cambridge University Press, 1988, págs. 137-154.

Rawls, J., Political Liberalism, Nueva York, Columbia University Press, 1996. Rawls, J., "Justice as Fairness: Political not Metaphysical", en Freeman, S. (ed.), John Rawls. Collected Papers, Cambridge, Harvard University Press, 2001.

Rawls, J., "The idea of an Overlapping Consensus", en Freeman, S. (ed.), John Rawls. Collected Papers, Cambridge, Harvard University Press, 2001. 
Rawls, J., "Kantian Constructivism in Moral Theory", en Freeman, S. (ed.), John Rawls. Collected Papers, Cambridge, Harvard University Press, 2001.

Raz J., "Facing Diversity: The Case of Epistemic Abstinence", en Raz, J., Ethics in the Public Domain. Essays in the Morality of Law and Politics, Oxford, Clarendon Press, 1995, págs. 60-96.

Sandel, M. J., Public Philosophy. Essays on Morality in Politics, Cambridge, Harvard University Press, 2005.

Scanlon, T. M., What we owe to each other, Cambridge, The Belknap Press of Harvard University Press, 1998.

Schmitt, A., "Las circunstancias de la tolerancia", Doxa, 11, 1992, págs. 71-85.

Silva-Herzog Márquez, J., "Razones para la tolerancia", en Vázquez, R. (comp.), Tolerancia y Pluralismo, Ciudad de México, Ediciones Coyoacán, 2005.

Taylor, C., Hegel and Modern Society, Cambridge, Cambridge University Press, 1979.

Williams, B., "Conflictos de valores", en Williams, B., La fortuna moral. Ensayos filosóficos 1973-1980, Ciudad de México, IIF-UNAM Williams, B., Morality: an Introduction to Ethics, Cambridge, Cambridge University Press, 1993. 